\title{
Análise da relação entre rentabilidade e estratégias de gestão do capital de giro das empresas listadas na $\mathrm{B3}$
}

\author{
Analysis of the relationship between profitability and working capital management \\ strategies of companies listed in B3
}

Análisis de la relación entre rentabilidad y estrategias de gestión del capital de trabajo en las empresas listadas en B3

\section{Ilírio José Rech}

Doutor em Contabilidade e Controladoria (FEA/USP)

Professor dos Programas de Pós-Graduação em Ciências Contábeis (UFG e UFU)

Endereço: R. Samambaia, s/n - Campus Samambaia

CEP: 74.690-900 - Goiânia/GO - Brasil

E-mail: ilírio.jose@ufg.br

Telefone: (62) 3521-1390

\section{Moisés Ferreira da Cunha}

Doutor em Controladoria e Contabilidade (FEA/USP)

Professor do Programa de Pós-Graduação em Ciências Contábeis (UFG)

Endereço: R. Samambaia, s/n - Campus Samambaia

CEP: 74.690-900 - Goiânia/GO - Brasil

E-mail: moises_cunha@ufg.br

Telefone: (62) 3521-1390

\section{Carolina Teixeira Rabelo}

Graduada em Ciências Contábeis (UFU)

Endereço: Avenida José Messias da Silva, $n^{\circ}$ 66, Bairro: Bosque

CEP: 38446-075 - Araguari/MG - Brasil

E-mail: carolina.teixeira@ufu.br

Telefone: (34) 42423240

\section{Alessandra Carneiro Barbosa}

Graduada em Ciências Contábeis (UFU)

Endereço: Rua São Crispim no ${ }^{\circ}$, Bairro Sibipiruna

CEP: 38.445-128 Araguari/MG - Brasil

E-mail: alessandracbarbosa2@hotmail.com

Telefone: (34) 998960810

Artigo recebido em 09/11/2016. Revisado por pares em 22/08/2018. Reformulado em 04/03/2018. Recomendado para publicação em 25/03/2019 por Carlos Eduardo Facin Lavarda Editor-Chefe). Publicado em 31/03/2019. 


\section{Resumo}

O objetivo principal da administração do capital de giro é manter equilíbrio entre cada um de seus componentes e, com isso, o equilíbrio entre o risco de insolvência e a rentabilidade. A empresa pode, portanto, adotar uma política agressiva ou conservadora de administração do capital de giro, dependendo da estratégia da gestão. Nesse sentido, o objetivo deste artigo é analisar a influência das estratégias de gestão do capital de giro na rentabilidade das empresas listadas na B3. Foi, então, selecionada uma amostra de 152 empresas listadas na B3 e segregadas entre política agressiva ou conservadora de gestão do capital de giro. O período analisado foi de 2000 a 2014 e os dados coletados consistem de ativo circulante, passivo circulante, ativo total, rentabilidade do ativo total e rentabilidade do patrimônio líquido. Os dados foram organizados e analisados com base na regressão simples e multivariada. Os resultados indicam que a estratégia de investimento em capital de giro influencia positivamente a rentabilidade do ativo total e do patrimônio líquido. No que diz respeito à política de financiamento, verificou-se que as empresas, quando analisadas em conjunto, apresentaram influência negativa da agressividade de financiamento na rentabilidade do ativo e do patrimônio líquido. No entanto, as empresas que adotam agressividade na política de financiamento acima da média e apresentam rentabilidade sobre o ativo acima da média representam influência positiva da política de financiamento na rentabilidade.

Palavras-chave: Capital de giro; Rentabilidade; Estratégia agressiva; Estratégia conservadora

\section{Abstract}

The main purpose of working capital management is to maintain a balance between each of its components and, therefore, the balance between insolvency risk and profitability. The company can therefore adopt an aggressive or conservative policy of working capital management, depending on the management strategy. In this sense, the purpose of this article is to analyze the influence of working capital management strategies on the profitability of the companies listed in B3. It was then selected a sample of 152 companies listed in B3 and segregated between aggressive or conservative policy of working capital management. The period analyzed was from 2000 to 2014 and the data collected consists of current assets, current liabilities, total assets, total assets profitability and net assets' profitability. Data were organized and analyzed based on simple and multivariate regression. The results indicate that the investment strategy in working capital positively influences the profitability of total assets and shareholders' equity. As regards the financing policy, it was verified that the companies, when analyzed together, had a negative influence of the aggressiveness of financing on the profitability of assets and equity. However, companies that adopt aggressive financing policies above average and show above-average return on assets represent a positive influence of the financing policy on profitability.

Keywords: Working capital; Profitability; Aggressive strategy; Conservative strategy

\section{Resumen}

El objetivo principal de la administración del capital de trabajo es mantener el equilibrio entre cada uno de sus componentes y, con ello, el equilibrio entre el riesgo de insolvencia y la rentabilidad. La empresa puede, por lo tanto, adoptar una política agresiva o conservadora de administración del capital de trabajo, dependiendo de la estrategia de la gestión. En este sentido, el objetivo de este artículo es analizar la influencia de las estrategias de gestión del capital de trabajo en la rentabilidad de las empresas listadas en la B3. Se seleccionó una muestra de 152 empresas listadas en la B3 y separadas entre política agresiva o conservadora de gestión del capital de trabajo. El período analizado comprendió 2000-2014 y los datos colectados fueron los referidos a las cuentas activo circulante, pasivo circulante, activo total, rentabilidad del activo total y rentabilidad del patrimonio neto. Los datos fueron organizados 
y analizados empleando la regresión simple y multivariada. Los resultados indican que la estrategia de inversión en capital de giro influye positivamente en la rentabilidad del activo total y del patrimonio neto. En lo que se refiere a la política de financiamiento, se verificó que cuando se analizan los datos de del total de empresa, los resultados apuntan hacia una influencia negativa de la politica agresiva de financiamiento hacia la rentabilidad del activo y del patrimonio neto. Sin embargo, las empresas que están por encima de la media en políticas más agresivas y en los resultados de rentabilidad del activo, manifiestan una influencia positiva de la política de financiación sobre la rentabilidad.

Palabras clave: Capital de trabajo; Rentabilidad; Estrategia agresiva; Estrategia conservadora

\section{Introdução}

No mundo ideal da administração financeira de uma empresa, as vendas seriam à vista, as compras seriam a prazo e o estoque não existiria. Isso faria com que os investimentos de recursos próprios em capital de giro fossem zero. Assim, o retorno sobre o patrimônio líquido seria maximizado, uma vez que os investimentos em giro são vistos como não lucrativos. No entanto a ausência de recursos, rápida e oportunamente disponíveis, para honrar as obrigações de curto prazo eleva o risco de insolvência da empresa, apesar de sua rentabilidade.

Normalmente, as empresas têm, a sua disposição, opções para reduzir o investimento em ativos fixos por meio de aluguel ou leasing de máquinas e equipamentos, sem comprometer sua capacidade produtiva e indicadores. Entretanto não há alternativas para a empresa alterar os componentes do capital de giro sem comprometer seus indicadores, estrutura de capital ou nível de risco. Um nível elevado de passivos circulantes pode aumentar o risco de insolvência e, consequentemente, ter efeitos na estrutura de capital ou no risco observado pelos credores.

Uma gestão eficiente com nível adequado de capital de giro é aquela em que há equilíbrio entre risco e rentabilidade. Pesquisas realizadas por Shin e Soenen (1998), Deloof (2003), Sen e Oruç (2009), Afza e Nazir (2011) e Awan et al. (2014) revelam haver evidências estatísticas da relação entre a rentabilidade e sua eficiência na gestão do capital de giro. Da mesma forma, pesquisa efetuada por Hussain, Farooz e Khan (2012) constatou que as empresas que adotam baixo nível de ativos circulantes, aumentam a rentabilidade.

A gestão estratégica do capital de giro pode ser classificada em três níveis: agressiva, moderada ou conservadora. Estratégias agressivas envolvem baixo investimento de capital de giro e elevado volume de financiamento. Inversamente, elevado investimento em capital de giro e baixo volume de financiamentos são estratégias de baixo risco e baixo retorno, consideradas estratégias conservadoras (GITMAN, 2006; MOYER et al., 2012; HUSSAIN; FAROOZ; KHAN, 2012).

Outra forma de analisar a estratégia de investimentos é comparar a relação entre ativos circulantes e ativos fixos ou o total de ativos. Baixa relação significa estratégia agressiva, enquanto que uma relação elevada denota estratégia conservadora. (WEINRAUB; VISSCHER, 1998; AFZA e NAZIR, 2007; Al-SHUBIRI, 2011).

Pesquisa realizada por Anjos e Luz (2013) verificou que a maioria das empresas da indústria de transformação listadas na BMF\&Bovespa (atual B3), no período de 2003 a 2012. adotaram política conservadora do capital de giro. Medeiros e Rodrigues (2004) verificaram que as empresas da amostra de pesquisa procuraram manter um equilíbrio financeiro, usando recursos de longo prazo para financiar sua necessidade total de financiamento, o que denota uma estratégia conservadora.

No entanto, as pesquisas não verificaram se o comportamento da rentabilidade das empresas é influenciado pelas estratégias de gestão do capital de giro. Neste sentido, o objetivo deste artigo é analisar a influência das estratégias de gestão do capital de giro na rentabilidade 
das empresas listadas na B3. Para alcançar o objetivo, foi realizada uma análise quantitativa por meio de regressão simples e multivariada, tendo por base uma amostra de 152 empresas listadas na B3. Com suporte nos dados do período de 2000 a 2014, as empresas foram classificadas como de estratégia agressiva ou conservadora, de acordo com o volume de ativos e passivos circulantes.

Pesquisa de Nakamura et al. (2010) constatou que empresas com menor volume de estoques são propensos a ser mais lucrativas operacionalmente, sugerindo que companhias mais agressivas tendem a gerar mais rentabilidade, compensando os efeitos negativos de políticas agressivas de capital de giro. Os referidos autores usaram o ciclo de conversão de caixa, a requisição de capital de giro e ciclo de contas a receber e a pagar como proxies para a sua pesquisa. A presente investigação se distingue das demais por usar, em sua metodologia, a relação entre ativos circulantes e ativos fixos, bem como a relação de investimento em capital de giro e sua forma de financiamento para verificar a influência da estratégia de gestão do capital de giro sobre a rentabilidade das empresas.

O uso de proxies que relativizam os investimentos de giro em relação ao ativo total, bem como a forma de financiamento dos investimentos em giro, justifica-se por considerar o efeito tamanho das empresas, além de que, supostamente, corporações maiores têm maior acesso ou facilidade e estrutura para captação de crédito de curto prazo.

O Brasil tem se destacado no "Ranking Mundial de Juros Reais", elaborado pelo portal MoneYou e da Infinity Asset Management, como o melhor pagador de juros reais entre 40 países pesquisados pelo portal (MONEYOU, 2016). Somam-se, a isso, as taxas de juros de curto prazo dos demais países geralmente menores que as de longo prazo (Moyer et al., 2012). Assim, a presente pesquisa se justifica por analisar um país onde as taxas de juros de curto prazo, que afetam diretamente o ativo e passivo circulante, tendem a ser maiores que as de longo prazo, contrariando a lógica dos demais países cujas pesquisas já testaram a influência das estratégias de gestão do capital de giro.

Os resultados da pesquisa demonstram que empresas a adotarem estratégias mais agressivas podem ser compensadas com maior rentabilidade de ativos e patrimônio líquido. Inversamente, empresas com estratégias conservadoras podem ter sua rentabilidade afetada. Destaca-se que, nesta análise, assume-se o termo "podem" por admitir que essas não sejam as únicas variáveis a afetarem a rentabilidade das empresas. Nesse sentido, a presente pesquisa serve de suporte para os gestores estabelecerem uma política de capital de giro adequada à estratégia da empresa. Além disso, contribui para a comunidade de analistas e investidores, no que diz respeito às suas recomendações e decisões de investimentos em empresas mais agressivas ou conservadoras, de acordo com seu perfil.

A presente investigação está estruturada em quatro partes, além desta introdução. A segunda parte apresenta o referencial teórico em relação às estratégias de gestão do capital de giro e seus efeitos. Na terceira seção, é exposta a metodologia de pesquisa. Na quarta, são revelados os resultados e, por final, na quinta parte, as considerações finais.

\section{Referencial teórico}

\subsection{Natureza e importância do capital de giro}

O capital de giro é um fator importante para a manutenção da liquidez, solvência e rentabilidade de uma empresa. O tamanho e a natureza do capital de giro de uma empresa é função de diferentes fatores, tais como: tipo de produtos, ciclo e eficiência operacional, volume de vendas, políticas de crédito e estocagem, concorrência, entre outros.

Autores como Gitman (2006) Bodie e Merton (1999), Brigham, Gapenski e Ehrhardt (2001), Assaf Neto (2003) Assaf Neto e Silva (2002), Ross, Westerfield e Jaffe (1995) referem- 
se ao capital de giro como os elementos que têm como característica a condição de serem convertidos em caixa no prazo máximo de um período contábil.

A natureza do capital de giro está relacionada diretamente com as atividades da empresa. No decorrer do processo produtivo, os recursos se transformam de caixa em estoque de matériaprima, e esta se converte em produtos. Estes, por sua vez, por meio do processo de venda, transformam-se em valores a receber. Por fim, tornam-se caixa novamente pelo recebimento de vendas, completando o ciclo das atividades operacionais. Com base nesse ciclo, do ponto de vista financeiro, os principais componentes que compõem o capital de giro são: as disponibilidades, as contas a receber e os estoques no ativo circulante ${ }^{\mathrm{i}}$; as contas a pagar e os empréstimos no passivo circulante.

A diferença entre o ativo circulante e o passivo circulante é, usualmente, definida como capital de giro líquido ou capital circulante líquido (CCL). Se o valor do ativo circulante superar o valor do passivo circulante, diz-se que se tem CCL positivo e, no caso de o passivo exceder o valor do ativo circulante, tem-se um CCL negativo.

A presença de capital de giro líquido positivo pode representar a expectativa de solvência e maior probabilidade de sucesso das operações da empresa. Enquanto que um capital de giro líquido negativo pode ser interpretado como risco de insolvência e, consequentemente, como fracasso da administração na gestão do capital de giro. Porém, essa externalidade de solvência, sucesso ou fracasso, atribuída ao capital de giro líquido pode estar relacionada à estratégia que a empresa adota na gestão desses recursos.

A importância do capital de giro está relacionada às decisões do nível de investimento em capital de giro e de seu financiamento. As empresas devem determinar o impacto que essas duas decisões têm sobre sua rentabilidade e risco. O impacto da administração do capital de giro na rentabilidade é fundamental porque as empresas necessitam de equilíbrio entre risco e lucro para atingir um nível ótimo de capital de giro, aqui entendido como aquele que maximiza a riqueza dos acionistas sem colocar em risco o investimento.

Um dos trabalhos pioneiros para analisar os efeitos ou a relação entre políticas de capital de giro e rentabilidade foi realizado por Shin e Soenen (1998). Os autores encontraram relação negativa entre ciclo de caixa e rentabilidade em uma amostra de empresas estadunidenses, no período de 1975 a 1994. No mesmo sentido, Deloof (2003), analisando 1009 empresas belgas no período de 1992 a 1996, também detectou forte relação negativa entre prazos médios dos itens do capital de giro e a rentabilidade das empresas, indicando que o gerenciamento do capital de giro está relacionado com a rentabilidade dos ativos.

Sabetfar e Sanatkar afirmam que a gestão adequada do capital de giro tem impacto significativo nos retornos excedentes das ações das empresas e desempenha um papel fundamental na criação de valor para os acionistas, melhorando o valor das empresas. Pesquisas realizadas por Wang (2002), Narware (2004), Karachi, Arcos e Benevides (2006), Padachi (2006), Shan e Sana (2006), Afza e Nazir (2007) encontraram forte relação entre rentabilidade e os componentes do capital de giro. Os resultados sugerem que baixos investimentos em capital de giro estão associados à alta rentabilidade e vice-versa.

Apesar de os estudos demonstrarem a influência no risco e na rentabilidade das empresas, não é possível afirmar que a política de capital de giro de uma empresa possa ser aplicada com eficiência a outra. Isso significa que não há uma política de investimento ou financiamento de capital em giro que possa ser considerada ótima para todas as empresas (BREALEY; MYERS; ALLEN, 2014).

Nesse sentido é que se destaca a importância do capital de giro e a necessidade de os gestores buscarem o ponto de equilíbrio entre rentabilidade e risco, levando em consideração as características intrínsecas de cada empresa. Os gestores podem usar tais características para aumentar a competitividade e tornar as empresas mais rentáveis, mantendo um nível adequado de capital de giro. 


\subsection{Fatores que interferem no capital de giro}

Entre os fatores de sucesso de uma empresa, a administração do capital de giro tem presença garantida, pois de nada adianta uma empresa ter boas previsões de longo prazo se tem seu curto prazo comprometido. Para Padachi (2006), entre os fatores de sucesso ou fracasso das empresas, destacam-se as condições e disponibilidade de financiamentos como um dos elementos externos e as habilidades da administração na gestão do capital de giro como fatores internos. O mesmo autor compara o capital de giro ao sangue necessário ao corpo humano para manter a vida; assim é a importância do capital de giro para manter a empresa em funcionamento.

O ciclo operacional de uma corporação, normalmente, consiste em três atividades: comprar (matérias-primas/produtos e serviços), produzir e vender os produtos. Essas operações geram fluxos de caixa não sincronizados, devido às incertezas nos prazos de compras, produção e recebimentos das vendas. Quanto maior este ciclo, maior será o volume de recursos investidos em capital de giro, pois essas atividades têm relação direta com o capital de giro e, por consequência, com a rentabilidade da empresa.

Uma política de crédito mais branda, com o estabelecimento de prazos maiores para os clientes, pode alavancar as vendas. Porém, seu impacto nas contas a receber nem sempre é proporcional ou linear às vendas. Clientes que possuem hábitos de comprar à vista podem optar por comprar a prazo, dependendo dos termos oferecidos, drenando os recursos para duplicatas a receber.

Um aumento nas vendas tem efeitos nos elementos do capital de giro. Considerando que elas possam ser resultado de um abrandamento no prazo, também provocam a necessidade de aumentar os recursos investidos em estoques. Para Moyer et al. (2012), os estoques servem como um amortecedor entre as várias fases do ciclo de produção-venda de uma empresa, dando flexibilidade na compra de matérias-primas e produção. $\mathrm{O}$ aumento de estoques, tanto de matéria-prima como de produtos acabados, pode representar maior conforto para a área de compras, produção e vendas. Mas esse "conforto" provocará elevação do volume desses ativos que nem sempre podem ser financiados pelos fornecedores. Tal estratégia drenará uma parte dos recursos para estoques, dependendo da defasagem entre o ciclo operacional e o prazo de pagamento de fornecedores.

Os recursos aplicados nos estoques impactam na rentabilidade uma vez que, além de não renderem juros, provocam gastos e riscos com armazenagem, seguro, obsolescência, perdas etc. No entanto são indispensáveis, uma vez que a falta deles pode implicar a perda de vendas por ausência de matéria-prima ou produtos acabados a fim de atender a produção. Para Moyer et al. (2012), o estoque é um dos fatores mais importantes na gestão do capital de giro, dada a dificuldade de estimá-lo com precisão. A falta ou excesso de estoques afeta diretamente o ciclo operacional e, consequentemente, a rentabilidade e o risco da empresa.

Shin e Soenen (1998) pesquisaram a relação do ciclo operacional e a rentabilidade para uma amostra de empresas estadunidenses no período de 1975-1994. Os autores encontraram forte relação negativa entre o ciclo de caixa, ciclo operacional e a rentabilidade para a amostra de companhias estudadas. Isso evidencia que a gestão adequada de contas a receber, fornecedores e estoques são fatores que contribuem para o sucesso das empresas os quais, além de garantirem a sobrevivência das mesmas, ainda fazem com que estas aumentem o lucro e o retorno para os acionistas.

Verifica-se dessa forma que as estratégias de gestão do capital de giro envolvem decisões sobre os ativos e passivos circulantes de uma empresa, como são usados e como a sua composição afeta o risco e retorno à empresa. Dada a natureza desses ativos e passivos, a sua falta ou excesso gera redução de rentabilidade e aumento do risco, seja pelo custo de mantêlos, pela perda de vendas ou perda de liquidez. 


\subsection{Trade-off entre risco e rentabilidade}

Geralmente, ativos circulantes representam parte significativa dos ativos totais de uma empresa. Contudo, a sua forma de gestão e análise não se assemelha aos demais ativos. Uma empresa tem poder de reduzir o investimento em ativos fixos, terceirizando o processo produtivo, alugando ou arrendando a planta industrial; porém, a mesma política não pode ser adotada para os componentes do capital de giro sem comprometer seu risco e indicadores analisados pelo mercado.

Assim, as empresas têm poucas alternativas para reduzir o capital de giro a não ser por meio de sua administração e controle. $\mathrm{O}$ volume ou a forma de financiamento do capital de giro, dependendo da estratégia adotada, pode impactar tanto na rentabilidade como no risco de insolvência da empresa.

Os investimentos em estoques e duplicatas a receber são considerados não lucrativos, tendo em vista que não são remunerados diretamente e o valor agregado para a empresa é menor que os proporcionados pelos ativos fixos. Assim, a falta de opções que deem, ao gestor, maior flexibilidade na gestão do capital de giro pode provocar excesso de recursos investidos nestes itens, comprometendo a rentabilidade. Por outro lado, a falta de recursos investidos em giro pode afetar a liquidez e levar a empresa à insolvência.

Um nível elevado de ativos correntes pode reduzir o risco de liquidez e insolvência, mas aumenta o custo de oportunidade dos recursos que poderiam estar investidos em ativos fixos de maior produtividade. Por outro lado, quanto menor o investimento nesses ativos, maior é o risco de insolvência da corporação e a possibilidade de a mesma recorrer a passivos de curto prazo. Isso pode comprometer a credibilidade da empresa junto a seus credores que aumentarão os juros e a exigência de garantias, voltando a comprometer a rentabilidade da empresa.

Os efeitos das variações do volume de ativos e passivos circulantes podem ser evidenciados por meio da relação entre os ativos circulantes e ativos totais (AC/AT) e passivos circulantes e ativos totais (PC/AT). A primeira relação representa a proporção dos ativos disponíveis para a empresa, aplicados no ativo circulante. A segunda relação reflete a parte dos ativos disponíveis pela empresa que são financiados pelas obrigações de curto prazo.

A relação AC/AT tem influência na rentabilidade da empresa e a relação PC/AT está relacionada ao risco da empresa. O termo rentabilidade, aqui, é utilizado como a relação entre as receitas e custos gerados pelo uso dos ativos nas operações da empresa. E o termo risco, como a probabilidade de a empresa não possuir recursos para honrar seus compromissos nos prazos estabelecidos.

O Quadro 1 faz um resumo dos efeitos das variações nos ativos circulantes e passivos circulantes sobre o risco e a rentabilidade destacados por Gitman (2006).

Quadro 1 - Efeitos da variação de quocientes sobre lucros e risco

\begin{tabular}{|l|c|c|c|}
\hline \multicolumn{1}{|c|}{ Relação } & Variação do quociente & Efeito sobre o lucro & Efeito sobre o risco \\
\hline Ativos Circulantes/ Ativos Totais & Aumento & Diminuição & Diminuição \\
& Redução & Aumento & Aumento \\
\hline Passivos Circulantes/Ativos totais & Aumento & Aumento & Aumento \\
& Redução & Diminuição & Diminuição \\
\hline
\end{tabular}

Fonte: Gitman (2006)

Neste quadro, ceteris paribus, verifica-se que um aumento nos ativos circulantes provoca uma redução na rentabilidade e no risco. Por outro lado, uma redução nestes acarreta um aumento na rentabilidade e no risco. Da mesma forma, um aumento no passivo circulante provoca um aumento na rentabilidade e no risco, cujo inverso ocasiona uma redução tanto na rentabilidade como no risco. 
Estratégias de gestão mais agressivas, mantendo um nível menor de investimentos em giro, podem levar à maior rentabilidade, porém os riscos de insolvência e de captação de recursos mais caros também estarão presentes. Por outro lado, estratégias mais conservadoras de investimentos em giro asseguram maior garantia de solvência; contudo, podem gerar menor rentabilidade da empresa.

Assim, um dos principais objetivos da administração da empresa é minimizar o volume de investimentos em ativos circulantes e maximizar o uso de recursos de terceiros não remunerados, como salários a pagar e impostos que, normalmente, não acarretam cobrança explícita de juros e de financiamento de longo prazo. Quando alcançado esse objetivo, a administração terá assegurado, à empresa, um equilíbrio entre risco e rentabilidade.

Entretanto, Vishnani e Shah (2007), analisando 23 empresas indianas da indústria eletrônica, não encontraram correlação significativa entre as políticas de capital de giro e rentabilidade, muito embora os autores destaquem que, para algumas empresas, essa relação exista. Enfatiza-se que este pode ser um efeito relacionado ao setor.

No Brasil, evidencia-se a pesquisa de Sato (2007) que investigou 16 empresas do setor de tecidos, listadas na Bovespa (atual B3) nos períodos de 1997 a 2006 e não encontrou evidências da relação entre rentabilidade e liquidez. Ressalta-se que esta pesquisa analisou os índices de liquidez com base no modelo dinâmico de Fleuriet, não sendo possível afirmar que os resultados revelados sejam opostos aos encontrados pelos estudos citados.

Embora apenas um estudo tenha utilizado como Proxy a relação entre ativo circulante/ativo total e passivo circulante/ativo total, essa junção pode existir, uma vez que os prazos médios usados na maioria dos trabalhos são calculados com base nos componentes do ativo e do passivo circulante. Esses resultados demonstram haver forte relação entre os componentes do capital de giro e rentabilidade ainda que as formas de mensurá-la sejam diferentes nos diversos estudos.

\subsection{Estratégias de administração do capital de giro}

Se o ideal para uma administração de capital de giro é que as vendas sejam à vista, as compras a prazo e os estoques inexistentes, essa administração deve procurar se aproximar desse ideal. Porém, o mercado consumidor e fornecedor com o qual a empresa se relaciona também buscarão esse mesmo padrão. Assim, haverá, de ambos os lados, certa pressão nas contas a receber e nas contas a pagar, cada um buscando a melhor posição para seus negócios, embora nem sempre seja possível chegar a um equilíbrio entre o mercado fornecedor e consumidor.

Nesse ponto, surgem as estratégias que cada companhia ou administrador adota para maximizar o lucro da empresa. Todavia, a estratégia que apresenta maior retorno para o acionista é a que apresenta ativo circulante mínimo e o máximo possível de passivo de longo prazo, fazendo com que as atividades sejam financiadas por capital de terceiros.

Mas essa estratégia expõe a empresa às variações da economia onde está inserida. Em um momento de restrição de crédito, a firma pode sucumbir diante da falta de recursos para honrar seus compromissos. Neste sentido, ela pode optar por uma estratégia de capital de giro agressiva ou conservadora. De acordo com Gitman (2006), uma estratégia agressiva ou conservadora é definida em função do volume de recursos investidos no ativo circulante ou pela forma de financiamento desses recursos.

Brigham, Gapenski e Ehrhardt (2001) e Shah e Sana (2006) destacam que as empresas podem adotar três políticas alternativas em relação à quantidade de ativos circulantes: a política ou abordagem relaxada, com volume relativamente grande em estoques e créditos e a política de vendas bem liberal; a política ou abordagem restritiva na qual o volume de recursos no ativo 
circulante é menor, fazendo com que seu giro seja maior; e uma política ou abordagem moderada que se situa entre a política relaxada e restritiva.

Gitman (2006) ressalta que as estratégias podem ser agressivas ou conservadoras, porém em relação à forma de financiamento. Esse autor separa os ativos em permanentes e sazonais em que, nos primeiros, estão compreendidos os ativos fixos mais uma parcela do circulante que permanece inalterado durante o ano. Na parcela sazonal, estão os ativos circulantes temporários que oscilam durante o ano.

Uma estratégia agressiva por parte da empresa consistiria em financiar os ativos sazonais e parte dos ativos permanentes com recursos de curto prazo. E uma estratégia conservadora incidiria em financiar todas as necessidades financeiras com recursos de longo prazo.

Por outro lado, Afza e Nazir (2007) apontam que uma política agressiva ou conservadora na administração do capital de giro está na relação entre os ativos de curto prazo e os ativos totais, de modo que um volume menor de ativos circulantes em relação ao ativo total representaria uma política agressiva de gestão do capital de giro. Um volume maior de ativos circulantes em relação ao ativo total conceberia uma política conservadora da gestão do capital de giro.

Os mesmos autores também identificam políticas agressivas e conservadoras no modo em que os ativos são financiados. Assim, classificam uma política agressiva quando a relação entre financiamentos de curto prazo e ativo total é maior, significando que a empresa utiliza maior volume de recursos de curto prazo para financiar suas operações. E uma política conservadora, quando a relação de passivos de curto prazo versus ativo total é menor, representando que a empresa financia suas operações com maior volume de recurso de longo prazo ou capital próprio.

Weinraub e Visscher (1998) analisaram um grupo de dez diferentes tipos de indústrias da base de dados da Compustat para verificar a utilização de uma política agressiva ou conservadora de ativos e passivos. Os autores chegaram à conclusão de que as empresas buscam equilibrar a forma de administrar o capital de giro, compensando uma política agressiva para a administração dos ativos circulantes com uma política relativamente conservadora na política de financiamento dos ativos ou vice-versa.

\section{Metodologia da pesquisa}

O objetivo do estudo é testar as premissas de que uma estratégia agressiva ou conservadora de financiamento ou investimento no capital de giro influencia a rentabilidade das empresas. Com base em uma pesquisa descritiva quantitativa, fundamentada em análise de regressão simples e multivariada (MARTINS; THEOFILO, 2007), foram estudados os dados anuais das demonstrações financeiras consolidadas de empresas brasileiras abertas, disponíveis na base de dados da Economática ${ }^{\circledR}$.

O período de tempo pesquisado compreende os anos de 2000 a 2014. Todas as empresas participantes da amostra possuíam ações ordinárias $(\mathrm{ON})$ negociadas na B3. Da amostra inicial, foram excluídas aquelas que não possuíam dados em todos os períodos, resultando em um total de 152. Essas empresas pertencem a 18 setores de atividades, tais como: alimentos e bebidas, têxtil, siderurgia, metalurgia, eletrônica, serviços, entre outros. As corporações do setor financeiro e de seguros não foram consideradas por possuírem estrutura de capital e características de ativos e passivos circulantes diferenciados das demais empresas, o que pode afetar os resultados. Os dados foram analisados com o auxílio do software estatístico SPSS.

Para avaliar a estratégia de gestão do capital de giro, neste estudo, utilizaram-se os conceitos de estratégia agressiva e conservadora de Afza e Nazir (2007), identificada tanto no volume de ativos circulantes como na maneira de financiar esses ativos. Da mesma forma que os autores, para detectar uma estratégia agressiva ou conservadora de investimento nos ativos, 
utiliza-se a relação entre ativos circulantes e ativo total. Uma relação maior entre esses ativos indica uma estratégia conservadora; uma relação menor sugere uma estratégia agressiva de gestão de capital de giro.

Assim, a variável independente Investimentos em Ativos Circulantes (IAC) é definida da seguinte forma: AC/AT $=$ IAC (Ativo Circulante $/$ Ativo Total $=$ Investimentos em ativos circulantes).

Em relação ao financiamento dos ativos circulantes (FAC), emprega-se a relação entre o passivo circulante e o ativo total. Desse modo, um valor maior nessa relação significa uma estratégia agressiva de financiamento dos ativos e um valor menor constitui uma estratégia conservadora de financiamento dos ativos. Logo, a variável independente financiamento dos ativos circulantes (FAC) é, assim, definida: $\mathrm{PC} / \mathrm{AT}=\mathrm{FAC}$ (Passivo circulante / Ativo Total $=$ Financiamento dos ativos circulantes).

A medida de rentabilidade utilizada como variável dependente é o retorno sobre os ativos (ROA) e o retorno sobre o patrimônio líquido médio (ROEM).

\section{Análise dos Dados}

Para realizar os testes, foram assumidas algumas premissas básicas empregadas em amostragens estatísticas, como a do Teorema Central do Limite. De acordo com Triola (1999, p 127), "na medida em que o tamanho da amostra aumenta, a distribuição amostral das médias amostrais tende para uma distribuição normal". Com base nesta proposição, partiu-se da premissa de que as variáveis possuem uma distribuição normal.

Na primeira regressão, objetivou-se verificar a relação entre a estratégia de financiamento e de investimento no capital de giro e a rentabilidade dos ativos. A Tabela 1 apresenta os resultados obtidos na regressão. Uma relação positiva significa que a estratégia de investimento em giro influencia positivamente a rentabilidade das empresas e vice-versa:

Tabela 1 - Relação entre a IAC e FAC e a rentabilidade do ativo e do PL no modelo regressão multivariada

\begin{tabular}{ccccccllrrrr}
\hline \multicolumn{3}{c}{ Tabela A } & \multicolumn{1}{c}{ Tabela B } \\
\hline Modelo & B & Std. Error & Beta & t & Sig. & Modelo & B & Std. Error & Beta & t & Sig. \\
(Constante) & 3,52 & 0,477 & & 7,381 & 0,00 & (Constant) & 4,695 & 1,813 & & 2,589 & 0,01 \\
IACC & 9,764 & 1,032 & 0,189 & 9,464 & 0,00 & IAC & 34,937 & 3,92 & 0,179 & 8,913 & 0,00 \\
FAC & $-12,71$ & 1,541 & $-0,17$ & $-8,25$ & 0,00 & FAC & $-39,13$ & 5,854 & $-0,13$ & $-6,69$ & 0,00 \\
\hline
\end{tabular}

Variável Dependente: ROA $\quad$ Variável Dependente: ROEM

Fonte: Dados da pesquisa

Pelos dados da Tabela 1, verifica-se que, tanto para a variável dependente ROA como para o ROEM, todas as variáveis são significativas a um nível de $95 \%$ e intervalo de confiança de $5 \%$. Para a variável dependente ROA, constata-se que o coeficiente da variável IAC apresenta sinal positivo, demonstrando que este tem relação positiva com a rentabilidade do ativo. Isso significa que uma maior relação entre o ativo circulante e o ativo total faz aumentar o retorno sobre o ativo total. Por outro lado, nota-se que a variável FAC (financiamento dos ativos circulantes) tem coeficiente negativo. Isso denota que uma relação maior entre o passivo circulante e o ativo total faz com que diminua o retorno sobre o ativo total. Os mesmos resultados são válidos também para o retorno sobre o patrimônio líquido.

Para confrontar os resultados da regressão multivariada, os mesmos testes foram realizados com base no modelo de regressão simples. A Tabela 2 exibe os resultados. 
Tabela 2 - Relação entre IAC e FAC e a rentabilidade do ativo e do PL no modelo regressão simples

\begin{tabular}{|c|c|c|c|c|c|c|c|c|c|c|c|}
\hline Model & B & Std. Error & Beta & $\mathbf{t}$ & Sig. & Model & B & Std. Error & Beta & $\mathbf{t}$ & Sig. \\
\hline (Constant) & 1,713 & 0,428 & & 4 & 0,00 & (Constant) & $-0,879$ & 1,621 & & $-0,54$ & 0,59 \\
\hline IAC & 5,741 & 0,919 & 0,111 & 6,248 & 0,00 & IAC & 22,563 & 3,479 & 0,116 & 6,485 & 0 \\
\hline (Constant) & 5,638 & 0,427 & & 13,2 & 0,00 & (Constant) & 12,285 & 1,621 & & 7,579 & 0 \\
\hline FAC & $-5,81$ & 1,377 & $-0,08$ & $-4,222$ & 0,00 & FAC & $-14,49$ & 5,225 & $-0,05$ & $-2,77$ & 0,01 \\
\hline
\end{tabular}

Fonte: Dados da pesquisa

Da mesma forma que no modelo de regressão multivariada, verifica-se que as variáveis são significativas a um nível de $95 \%$ e intervalo de confiança de 5\%. Apesar de os coeficientes apresentarem valores diferentes, nota-se que, tanto para o ROA quanto para o ROEM, o sinal é positivo para o IAC e negativo para o $\mathrm{FAC}$, confirmando os resultados da regressão multivariada. Esses resultados também foram confirmados na análise com o patrimônio líquido do final de cada período. A Tabela 3 ostenta os resultados.

Tabela 3 - Relação entre a IAC e FAC e a rentabilidade do PL no modelo regressão multivariada

\begin{tabular}{cccccc} 
Model & B & Std. Error & Beta & T & Sig. \\
(Constant) & $-4,17$ & 11,176 & & $-0,373$ & 0,7 \\
IAC & 85,35 & 24,177 & 0,072 & 3,53 & 0 \\
FAC & -133 & 36,11 & $-0,08$ & $-3,69$ & 0 \\
\hline
\end{tabular}

Fonte: Dados da pesquisa

$\mathrm{Na}$ análise dos coeficientes das variáveis, constata-se que a variável FAC apresenta uma relação inversa com a rentabilidade do patrimônio líquido médio, o que confirma as expectativas, tendo em vista que, quanto maior o passivo circulante, maior podem ser as despesas com juros, porque isso pode representar um risco de insolvência e os credores aumentarem o custo do capital.

A variável IAC também deveria oferecer coeficiente negativo, pois, conforme já analisado anteriormente, quanto maior a relação entre ativo circulante/ativo total, menor seria a expectativa de rentabilidade do ativo, o que não se confirma neste caso. Porém, há de se contrapor que seria necessário verificar se o aumento no ativo circulante provocou um aumento nas vendas e, com isso, aumento na rentabilidade; no entanto, não é o objetivo deste artigo.

Assim, os resultados dessa regressão levam a inferir que a estratégia de financiamento do capital de giro influencia negativamente a rentabilidade do patrimônio líquido e do ativo total. Em contrapartida, nos resultados da análise da estratégia de investimento em capital de giro, verifica-se que essa influencia diretamente a rentabilidade do patrimônio líquido e do ativo total. Esses resultados demonstram que as empresas com estratégia conservadora, tanto no investimento em capital de giro como no financiamento em capital de giro, obtêm maior rentabilidade.

O estudo de Weinraub e Visscher (1998) revelou que as companhias podem adotar uma política de compensação entre uma estratégia agressiva na gestão do passivo circulante com uma conservadora no ativo circulante ou vice-versa. Para verificar se essa situação se repete nos empreendimentos brasileiros, realizou-se uma regressão multivariada com as empresas que estão acima da média de investimento em capital de giro e com as empresas que estão acima da média de financiamento em giro. Os dados da Tabela 4 refletem os resultados encontrados, tanto para a estratégia de financiamento acima quanto abaixo da média. 
Tabela 4 - Segregação das empresas pela estratégia de financiamento acima e abaixo da média

\begin{tabular}{|c|c|c|c|c|c|c|c|c|c|c|c|}
\hline \multicolumn{6}{|c|}{ FAC acima da média } & \multicolumn{6}{|c|}{ FAC abaixo da média } \\
\hline Model & B & Std. Error & Beta & $\mathrm{t}$ & Sig. & Model & $\mathrm{B}$ & Std. Error & Beta & $\mathrm{t}$ & Sig. \\
\hline (Constant) & $-0,699$ & 2,111 & & $-0,331$ & 0,74 & (Constant) & 7,848 & 4,062 & & 1,932 &, 054 \\
\hline FAC & 43,116 & 13,952 & 0,089 & 3,09 & 0,002 & FAC & $-64,204$ & 10,102 &,- 155 & $-6,356$ &, 000 \\
\hline IAC & 10,325 & 3,546 & 0,083 & 2,912 & 0,004 & IAC & 48,944 & 6,151 & ,193 & 7,958 &, 000 \\
\hline \multicolumn{6}{|c|}{ Variável Dependente: ROE } & \multicolumn{6}{|c|}{ Variável Dependente: ROE } \\
\hline (Constant) & 0,589 & 0,706 & & 0,835 & 0,404 & (Constant) & 4,865 & 1,021 & & 4,764 &, 000 \\
\hline FAC & 11,016 & 4,664 & 0,067 & 2,362 & 0,018 & FAC & $-17,013$ & 2,539 &,- 163 & $-6,700$ &, 000 \\
\hline IAC & 7,779 & 1,185 & 0,185 & 6,563 & 0 & IAC & 10,444 & 1,546 &, 165 & 6,755 & ,000 \\
\hline
\end{tabular}

Fonte: Dados da pesquisa

A Tabela 4 evidencia que as empresas que mantêm uma estratégia de financiamento com uma relação superior à média das empresas, diferentemente da análise no quadro geral, revelam relação positiva tanto para IAC quanto para a FAC. Essa mesma relação não foi encontrada nas corporações que possuem uma estratégia de financiamento dos ativos abaixo da média. Nesse caso, verifica-se que o sinal do coeficiente para o IAC é positivo tanto para o ROA quanto para o ROE e negativo para o FAC.

Esses resultados sugerem que as empresas que utilizam uma estratégia mais agressiva de financiamento do capital de giro acima da média podem estar usando esse como um meio para financiar o ativo circulante, beneficiando-se por disponibilizarem mais crédito e estoques para giro, da mesma forma que foi analisado o resultado das empresas que estão acima e abaixo da média na estratégia de financiamento do capital de giro. Os resultados dos testes baseados na segregação das empresas estão apresentados na Tabela 5.

Tabela 5 - Segregação das empresas pela estratégia de investimento acima e abaixo da média

\begin{tabular}{|c|c|c|c|c|c|c|c|c|c|c|c|}
\hline \multicolumn{6}{|c|}{ IAC acima da média } & \multicolumn{6}{|c|}{ IAC abaixo da média } \\
\hline Model & B & $\begin{array}{l}\text { Std. } \\
\text { Error }\end{array}$ & Beta & $\mathrm{t}$ & Sig. & Model & B & $\begin{array}{l}\text { Std. } \\
\text { Error }\end{array}$ & Beta & $\mathrm{t}$ & Sig. \\
\hline (Constant) & 4,191 & 2,805 & & 1,494 & , 135 & (Constant) & $-8,931$ & 5,642 & & $-1,583$ & ,114 \\
\hline FAC & $-68,460$ & 8,614 &,- 199 & $-7,947$ &, 000 & FAC & $-18,384$ & 7,990 &,- 064 & $-2,301$ &, 022 \\
\hline IAC & 70,139 & 10,575 &, 166 & 6,633 &, 000 & IAC & 43,402 & 9,326 &, 129 & 4,654 &, 000 \\
\hline \multicolumn{6}{|c|}{ Variável Dependente: ROEM } & \multicolumn{6}{|c|}{ Variável Dependente: ROEM } \\
\hline (Constant) & 3,225 & ,709 & & 4,549 & ,000 & (Constant) & 1,123 & 1,559 & & ,721 & 471 \\
\hline FAC & $-12,747$ & 2,177 &,- 148 & $-5,854$ &, 000 & FAC & $-12,961$ & 2,208 &,- 161 & $-5,871$ &, 000 \\
\hline IAC & 11,900 & 2,673 &, 113 & 4,452 &, 000 & IAC & 13,422 & 2,577 &, 143 & 5,208 &, 000 \\
\hline
\end{tabular}

Fonte: Dados da pesquisa

Os resultados da Tabela 5 mostram não haver diferença entre as empresas que estão acima ou abaixo da média no quesito de política de investimentos. Tanto as mais agressivas quanto as conservadoras apresentaram coeficiente negativo para a variável FAC e um coeficiente positivo para a variável IAC. Os resultados dessa análise estão no mesmo sentido dos resultados encontrados na análise das empresas sem a segregação com base na média da variável IAC.

No entanto, esses resultados levaram em consideração a política de investimento e de financiamento do capital de giro. Contudo, o trade-off entre rentabilidade e risco pode afetar essa relação. Empresas com maior rentabilidade podem incorrer em maior risco sem, necessariamente, afetar o seu acesso ao crédito. Para verificar esse comportamento nas 
empresas da amostra, segregou-se aquelas com rentabilidade acima e abaixo da média. A Tabela 6 apresenta os resultados da regressão multivariada.

Tabela 6 - Segregação das empresas acima e abaixo da média do ROA

\begin{tabular}{|c|c|c|c|c|c|c|c|c|c|c|c|}
\hline \multicolumn{6}{|c|}{ ROEM/ROA acima da média } & \multicolumn{6}{|c|}{ ROEM/ROA abaixo da média } \\
\hline & B & $\begin{array}{c}\text { Std. } \\
\text { Error }\end{array}$ & Beta & & Sig. & & & $\begin{array}{l}\text { Std. } \\
\text { Error }\end{array}$ & Beta & $\mathrm{T}$ & Sig. \\
\hline (Constant) & 6,963 & ,625 & & 11,147 & ,000 & (Constant) & $-3,134$ & 2,245 & & $-1,396$ & , 163 \\
\hline FAC & 8,992 & 2,251 &, 116 & 3,994 & ,000 & FAC & $-74,037$ & 7,017 &,- 296 & $-10,552$ &, 000 \\
\hline IAC & 2,398 & 1,274 &, 055 & 1,882 &, 060 & IAC & 40,729 & 5,351 & ,214 & 7,611 &, 000 \\
\hline \multicolumn{6}{|c|}{ Variável Dependente: ROEM } & \multicolumn{6}{|c|}{ Variável Dependente: ROEM } \\
\hline (Constant) & $-21,160$ & 20,473 & & $-1,034$ & ,301 & (Constant) &,- 160 & ,539 & &,- 296 & ,767 \\
\hline FAC & $-201,475$ & 63,999 &,- 091 & $-3,148$ & ,002 & FAC & $-10,316$ & 1,685 &,- 176 & $-6,122$ &, 000 \\
\hline IAC & 119,045 & 48,806 & 071 & 2,439 &, 015 & IAC & 3,319 & 1,285 & ,074 & 2,583 &, 010 \\
\hline
\end{tabular}

Fonte: Dados da pesquisa

Com base na Tabela 6, verifica-se que as empresas com ROA acima da média apresentam os coeficientes das variáveis FAC e IAC positivos. Esse resultado é semelhante ao desfecho obtido com a segregação das empresas com FAC acima da média. No entanto, difere da análise do quadro geral, cujo coeficiente da variável FAC é negativo em todas as situações.

Esse achado sugere que uma estratégia de financiamento do capital de giro mais agressiva influencia a rentabilidade dos ativos, fazendo com que as empresas mais agressivas tenham retornos superiores à média. Entretanto, quando se analisa com base no ROEM, percebe-se que essa influência não se confirma, pois o coeficiente da variável FAC é negativo e da variável IAC é positivo.

Desta maneira, os resultados são inconclusivos para conferir a compensação de uma política agressiva de financiamento com uma política conservadora de investimento ou viceversa. Tais resultados diferem dos encontrados por Weinraub e Visscher (1998) nos quais as empresas por eles analisadas compensavam uma política agressiva de gestão do ativo circulante com uma política conservadora em relação ao financiamento, de modo a refletir certo equilíbrio entre as estratégias agressivas e conservadoras de gestão do capital de giro.

\section{Considerações finais}

Este estudo analisou se a rentabilidade das empresas é influenciada pelas estratégias da gestão de financiamento e investimento no capital de giro. Uma estratégia mais agressiva teria, como efeito, maior rentabilidade do ativo total e do patrimônio líquido, e uma estratégia conservadora de capital de giro, consequentemente, levaria a menor rentabilidade do ativo e do patrimônio líquido das empresas.

Constatou-se que a relação entre a estratégia de financiamento do capital de giro e ativos totais tem, na maioria dos casos, uma relação inversa com a rentabilidade. Isso evidencia que uma estratégia mais agressiva na gestão do financiamento, aumentando o passivo circulante como forma de financiar o ativo, influencia a rentabilidade das empresas. Da mesma maneira, uma estratégia conservadora na forma de financiamento pode aumentar a rentabilidade do ativo e do patrimônio líquido. Estes resultados estão em sintonia com os achados de Wang (2002).

No entanto, quando se trata de empresas que estão acima da média geral na agressividade do financiamento do capital de giro, encontrou-se uma relação positiva. $\mathrm{O}$ mesmo fator ocorreu nas companhias que possuem retorno sobre os ativos acima da média das empresas. Da mesma forma, no estudo de Weinraub e Visscher (1998), esses resultados sugerem que há um ponto de quebra de estrutura ou um ponto de equilíbrio entre política de financiamento e retorno do ativo. 
Diferente do estudo de Weinraub e Visscher (1998), esta conclusão somente se mostrou estatisticamente significativa na relação entre as estratégias de gestão do capital de giro e a rentabilidade do ativo total, não se observando um coeficiente de correlação significativo que sugerisse a influência da estratégia na rentabilidade do patrimônio líquido das empresas.

Por outro lado, verificou-se que a relação entre ativos circulantes e a rentabilidade dos ativos totais não apresentou influência inversa como esperado, levando em consideração que o valor agregado de seus elementos possui menor contribuição que os ativos fixos da empresa. Conforme destacado por Brigham, Gapenski e Ehrhardt (2001), Gitman (2006), Moyer et al. (2012), Brealey, Myers e Allen (2014), uma política conservadora com elevado volume de ativo circulante deveria reduzir a rentabilidade, porém esta hipótese não pode ser confirmada com base nos resultados encontrados.

Os resultados indicam haver influência direta da estratégia de investimentos no capital de giro na rentabilidade das empresas, conforme pode ser vista no sinal do coeficiente da variável IAC, destacado em todas as tabelas que apresentam os resultados da pesquisa. Porém esse desfecho sugere a necessidade de aprofundamento das investigações, uma vez que não foi verificado o efeito do aumento ou redução do ativo circulante no volume de vendas ou de custos das empresas. Esse efeito pode aumentar ou reduzir o lucro, compensando a capacidade de agregar valor dos ativos circulantes.

Os resultados detectados entre as empresas com IAC e FAC menor ou maior que a média indica que o comportamento da rentabilidade não é o mesmo para todas as companhias. Verificou-se que as firmas com FAC maior que a média apresentam uma relação positiva entre uma política agressiva e a rentabilidade, indicando influência da estratégia de gestão do capital de giro na rentabilidade das empresas. O mesmo ocorre com as empresas que têm retorno sobre os ativos maior que a média, contrariando os achados da pesquisa de Weinraub e Visscher (1998).

Pesquisas futuras podem ser realizadas para analisar o efeito de uma estratégia agressiva ou conservadora na administração de capital de giro em relação às vendas e custos das empresas e, assim, responder às causas da relação positiva entre a rentabilidade do ativo total e a relação ativo circulante/ativo total, encontradas neste estudo. Outras pesquisas também podem ser efetivadas, analisando as características da empresa que influenciam nas estratégias de administração do capital de giro.

\section{Referências}

AFZA, T. NASIR, M. S.. Is it better to be aggressive or conservative in managing Working Capital? Journal of Quality and Technology Management. V. 3 N. 2, 2007. p. 11-21

AFZA, T. NAZIR, M. S.. Working Capital Management Efficiency of Cement Sector of Pakistan. Journal of Economics and Behavioral Studies V. 2, N. 5, p. 223-235, May 2011.

Al-SHUBIRI, F. N. Analyzing the Relationship between Working Capital Management Policy and Operating Risk: An Empirical Study on Jordanian Industrial Companies. Hebron University Research Journal, V. 6, N. 1, 2011. p. 287-306

ANJOS, F. LUZ, A. R.. A gestão do capital de giro das indústrias de transformação listadas no Economática. X Congresso Online - Administração. Convibra 2013, Anais..., 2013.

ARCOS, M. A. BENAVIDES, J. Efecto del Ciclo de Efectivo Sobre la Rentabilidad de las Firmas Colombianas. Borradores de Economía y Finanzas. N. 9, Diciembre 2006. Disponível em: w.icesi.edu.co/dptoeni/publicaciones/docs. Acessado em 16/03/2015

ASSAF NETO, A. Finanças corporativas e valor. São Paulo: Atlas, 2003. 
ASSAF Neto, A., SILVA, C. A. T. Administração do capital de giro. $3^{\text {a }}$ Ed. São Paulo. Atlas, 2002.

AWAN, A. G. SHAHID, P. HASSAN, J. AHMAD, W.. Impact of working capital management on profitability of cement sector in Pakistan. International Journal of Business and Management Review. V.2, N.4, p.1-20, September 2014.

BODIE, Z., MERTON, R. C. Finanças. Porto Alegre, Bookman, 1999.

BREALEY, R.A., MYERS S. C., ALLEN, F.. Principles of corporate finance 11th Ed. New York, McGraw-Hill/Irwin, 2014.

BRIGHAM, E F., GAPENSKI, L. C. e EHRHARDT, Michael C. Administração financeira: teoria e prática. São Paulo: Atlas, 2001.

DELOOF, M. Does Working Capital Management Affect Profitability of Belgian Firms.

Journal of Business Finance \& Accounting v. 30, n. 3-4, p.573-588. 2003. DOI: 10.1111/1468-5957.00008.

GITMAN, L. J. Princípios de administração financeira. 10ª Ed. São Paulo, Pearson Addison Wesley, 2006.

GUAJARATI, D. N. Econometria básica. Tradução de Maria José Cyhlar Monteiro. Rio de Janeiro; Elsevier, 2006.

HUSSAIN, A., FAROOZ, S. U. KHAN, K.U. Aggressiveness and Conservativeness of Working Capital: A case of Pakistan Manufacturing Sector, European Journal of Scientific Research, V. 73, N. 2, 2012. p. 171-182

LAZARIDIS, I. TRYFONIDIS, D. The relationship between working capital management and profitability of listed companies in the Athens Stock Exchange. Journal of Financial Management and Analysis, V. 19, N. 1, January-June 2006.

MEDEIROS, O. R.. RODRIGUES, F. F. Questionando empiricamente a validade do modelo fleuriet. BASE - Revista de Administração e Contabilidade da Unisinos v. 1, n. 2, p.2532, setembro/dezembro. 2004.

MOYER, C. MCGUIGAN, J.R.. RAO, R. P.. KRETLOW, W. J. Contemporary Financial Management. $12^{\mathrm{a}} \mathrm{Ed}$. Cengage Learning, New York; .2012.

NAKAMURA, W. T.; FORTE, D.; BARROS, L. A. B. C.; CARDOSO, R. L. Capital Structure in Brazilian Small and Medium Enterprises: A panel study. XXXIV Encontro da ANPAD, Rio de Janeiro, 2010, Anais..., 2010.

NARWARE, P. C. Working Capital and Profitability - An Empirical Analysis, The Management Accountant, ICWAI, Kolkata, 2004.

PADACHI, K. Trends in Working Capital Management and its Impact on Firms' Performance: An Analysis of Mauritian Small Manufacturing Firms. International Review of Business Research Papers V.2 N. 2. October 2006.

MONEYOU, Ranking Mundial de Juros Reais - Set/16. Asset Infinity Managment.

Disponível e http://moneyou.com.br/wpcontent/uploads/2016/03/rankingdejurosreais010316.pdf.

ROSS, S. WESTERFIELD, R W. JAFFE, J. F. Administração Financeira. $2^{\text {a }}$ Ed. São Paulo, 2002. 
SABETFAR, P.. SANATKAR, M.. The Impact of Financing and Working Capital Management on the Company's Value. Magnt Research Report. V.3 n. 1. 2015. DOI: dx.doi.org/14.9831/1444-8939.2015/3-1/MAGNT.53.

SATO, S. S.. Análise econômica financeira setorial: Estudo da relação entre liquidez e rentabilidade sob a ótica do modelo dinâmico. 2007, 204 P. Dissertação (Mestrado) Escola de Engenharia de São Carlos. São Carlos-SP.2007.

SEN, M.. ORUÇ E.. Relationship between Efficiency Level of Working Capital Management and Return on Total Assets in ISE. International Journal of Business and Management, v. 4, n. 10, p. 109-114. 2009.

SHAH, S.M. A.. SANA, A. Impact of Working Capital Management on the Profitability of Oil and Gas Sector of Pakistan. European Journal of Scientific Research. V.15 N.3, 2006, p. 301-307. Disponível em http://www.eurojournals.com/ejsr\%2015\%203.pdf, Acessado em $15 / 07 / 2014$.

SHIN, H. H., SOENEN, L. Efficiency of working capital management and corporate profitability. Financial Practice and Education. V. 8, n. 2, p. 37-45, 1998.

TRIOLA. M. F. Introdução à estatística. $7^{\text {a }}$ Ed. LTC, Rio de Janeiro, 1999.

VISHNANI S.. SHAH B. K. Impact of working capital management policies on corporate performance - an empirical study. Global Business Review. 2007. Disponível em http://gbr.sagepub.com/cgi/content/abstract/8/2/267. Acessado em 05/03/2015.

WANG, Y.. Liquidity management, operating performance, and corporate value: evidence from Japan and Taiwan. Journal of Multinational Financial Management n. 12, p.159169, 2002. Disponível em: www.elsevier.com/locate/econbase. Acessado em 15/03/2015.

WEINRAUB, H. J. VISSCHER, S. Industry Practice relating to Aggressive / Conservative Working Capital Policies, Journal of Financial and Strategic decisions, V. 11, N. 2, 1998. p. 11-18

i O Comitê de Pronunciamentos Contábeis utiliza o termo ativo/passivo circulante e o IASB usa o termo current assets/liabilities que pode ser traduzido por ativo/passivo corrente ou circulante. Entende-se que os mesmos são sinônimos e a dupla utilização, no texto, busca melhorar a fluência em determinadas situações. 